(2) Open Access Full Text Article

\title{
Impact of Introducing the Pletaal Assist System on Drug Adherence in Outpatients with Ischaemic Stroke: A Pilot Study
}

\author{
Kazumasa Oura' \\ Ryo Itabashi' \\ Takashi Omoto ${ }^{2}$ \\ Mao Yamaguchi Oura' \\ Tetsuro Kiyokawa' \\ Eisuke Hirai' \\ Tetsuya Maeda' \\ 'Division of Neurology and Gerontology, \\ Department of Internal Medicine, School \\ of Medicine, Iwate Medical University, \\ Iwate, Japan; ${ }^{2}$ Department of Pharmacy, \\ Iwate Medical University Hospital, Iwate, \\ Japan
}

Correspondence: Kazumasa Oura Division of Neurology and Gerontology, Department of Internal Medicine, School of Medicine, Iwate Medical University, 2-I-I Idaidori, Yahaba-Cho, Shiwa-Gun, Iwate, 028-3695, Japan

Tel +8I-|9-6|3-7|II

Fax +8I-19-907-6933

Email koura@iwate-med.ac.jp
Purpose: The effectiveness of Electronic Medication Packaging devices for monitoring drug adherence has been widely reported. However, conventional devices are expensive for routine use and cannot confirm whether the medication was administered. We aimed to determine, in a pilot and feasibility study, the impact of introducing a new medication support device, the Pletaal Assist System ${ }^{\circledR}$, to monitor and improve cilostazol adherence for stroke prevention at an outpatient clinic.

Patients and Methods: We assessed consecutive patients treated with cilostazol for $>3$ months at our stroke outpatient clinic from January 2018 to March 2020. The adherence rate was assessed as follows: (the number of pills prescribed minus the number of remaining pills)/the number of pills prescribed. We compared the adherence rates before, during, and after Pletaal Assist System ${ }^{\circledR}$ usage, respectively.

Results: Overall, 25 patients (median age, 68.5 years; range, 51-86 years; male, 64\%) were enrolled. All participants were prescribed cilostazol $(100 \mathrm{mg})$ twice a day. There was no significant difference in the adherence rate among the three periods. However, in 10 patients with adherence rate below $100 \%$, the adherence rate during Pletaal Assist System ${ }^{\circledR}$ usage was higher than before usage $(99.5 \%$ vs $95 \%, \mathrm{p}=0.04)$, and the rate after using the Pletaal Assist System ${ }^{\circledR}$ tended to be lower compared to the rate during usage $(99.5 \%$ vs $96 \%$, $\mathrm{p}=0.05$ ).

Conclusion: Our preliminary evidence suggest that the Pletaal Assist System ${ }^{\circledR}$ could further improve cilostazol adherence in outpatients with poor drug adherence and may reduce the risk of recurrent strokes by improving adherence of patients with a history of stroke.

Keywords: medication adherence, antiplatelet drug, stroke, electronic medication packaging

\section{Introduction}

Poor medication adherence leads to significant worsening of illnesses, increased deaths, and increased health care costs. ${ }^{1-5}$ Approximately 33-69\% of medicationrelated hospitalizations in the United States are because of poor adherence, resulting in an annual cost of approximately $\$ 100$ billion. ${ }^{1-3}$

Antiplatelet therapy has been proven to be useful for preventing the recurrence of ischaemic stroke. ${ }^{6}$ However, discontinuing aspirin therapy could increase the risk of ischaemic stroke recurrence. ${ }^{7}$ The retention of antiplatelet use reportedly decreased to $79.3 \%$ one year after the first stroke and to $63.7 \%$ two years later in Swedish patients. ${ }^{8}$ Moreover, the retention rate for stroke prevention using drugs such as antithrombotic, antihypertensive, antihyperlipidemic, and antidiabetic drugs 
decreased to $75.5 \%$ three months after discharge in patients with ischaemic stroke or transient ischaemic attack. $^{9}$ A meta-analysis of 44 studies examining the relationship between medication adherence for cardiovascular disease (CVD), including antiplatelets, and CVD or allcause deaths showed that the risks of CVD and death were low in the group with good adherence. ${ }^{10}$

Although it is important to maintain a high rate of adherence with antiplatelet medication to prevent recurrent strokes, it may often be difficult for physicians to precisely quantify drug adherence for outpatients. The simplest method for monitoring drug adherence is self-reporting by patients. ${ }^{11,12}$ While self-reporting is easy, it can be misstated and cause health care providers to overestimate a patient's adherence. ${ }^{13}$ Recently, the usefulness of Electronic Medication Packaging (EMP) devices, which were included in a prescription drug package for adherence monitoring, has been reported. This system has five main components: i) it records dosing events and stores records of adherence; ii) it provides audio-visual reminders of the time of the next dose; iii) it consists of digital displays; iv) it has real-time monitoring; and v) it provides feedback on adherence performance. ${ }^{14}$ Although the conventional EMP device can confirm that the medicine container was opened, it is impossible to confirm whether the medicine was taken or how many tablets were taken.

Cilostazol, an antiplatelet drug that inhibits phosphodiesterase 3 for platelet aggregation, has been proven to reduce the recurrence of stroke in Japanese patients with non-cardioembolic stroke. ${ }^{15-17}$ The Pletaal Assist System ${ }^{\circledR}$ (PAS) (Otsuka Pharmaceutical, Tokyo, Japan) is a new medication support device that has been developed to record medication information and improve cilostazol adherence. The impact of introducing the PAS to monitor and improve drug adherence in patients with ischaemic stroke at an outpatient clinic has not yet been evaluated. We hypothesized that the use of the PAS could improve the adherence to cilostazol in patients with chronic stroke. Hence, this pilot study aimed to determine the impact of introducing the PAS on monitoring and improving cilostazol adherence for secondary prevention of stroke at an outpatient clinic.

\section{Methods}

\section{Study Population}

Consecutive stroke patients treated with cilostazol for $>3$ months at an outpatient clinic at the Division of Neurology and Gerontology, Iwate Medical University from January 2018 to March 2020 were assessed. Those who were at least 20 years of age were included. Patients who had contraindications for cilostazol (haemorrhagic diseases such as haemophilia, capillary fragility, intracranial haemorrhage, gastrointestinal bleeding, urinary bleeding, haemoptysis, vitreous haemorrhage, congestive heart failure, history of hypersensitivity to cilostazol components, and pregnancy) as well as those with symptoms that interfered with the use of the PAS, such as severe cognitive impairment, visual deficit, severe motor weakness, or other problems were excluded. All patients had mRS0 before stroke onset prior to participating in the trial. All patients provided written informed consent, and the study protocol complied with the ethical and institutional guidelines of the 2013 Declaration of Helsinki. The study was approved by the Ethics Committee of Iwate Medical University on January 24, 2018 and the approval number was H29-146.

\section{Evaluation of Drug Adherence}

The PAS was approved by the Japanese medical insurance as a free of charge package included with cilostazol prescriptions with the intention of functioning as an EMP. Figure 1 illustrates the appearance of the PAS to the patient. The PAS could contain and supply the drugs for up to four weeks. The light on the device would blink to prompt the patients to take out the drug. The time to flash the light was set by the pharmacist if the patient specified it when receiving the device, and then given to the patient. If the patient did not specify, the lights were set to blink at 6 a.m. and 6 p.m. When the drug was taken out, the light on the device would stop blinking. By using an application on a smartphone, the number of times the drug was taken out and the time were recorded. Cilostazol was prescribed for 12 weeks to each patient with three PAS devices containing four weeks' supply of cilostazol. The PAS was collected from the patients at our outpatient clinic 12 weeks after drug prescription.

\section{Adherence Assessment Methods}

The adherence rate was assessed as (the number of pills prescribed minus the number of remaining pills)/the number of pills prescribed. The remaining pills were counted by pharmacists who were blinded to the patient's information. We compared the adherence rates 12 weeks before starting the PAS (before PAS) to 12 weeks from starting the PAS (during PAS), and to 12 weeks after termination of the PAS (after PAS). Pill counts were performed thus a total of three times during outpatient visits: $12 \pm 2$ weeks after obtaining 


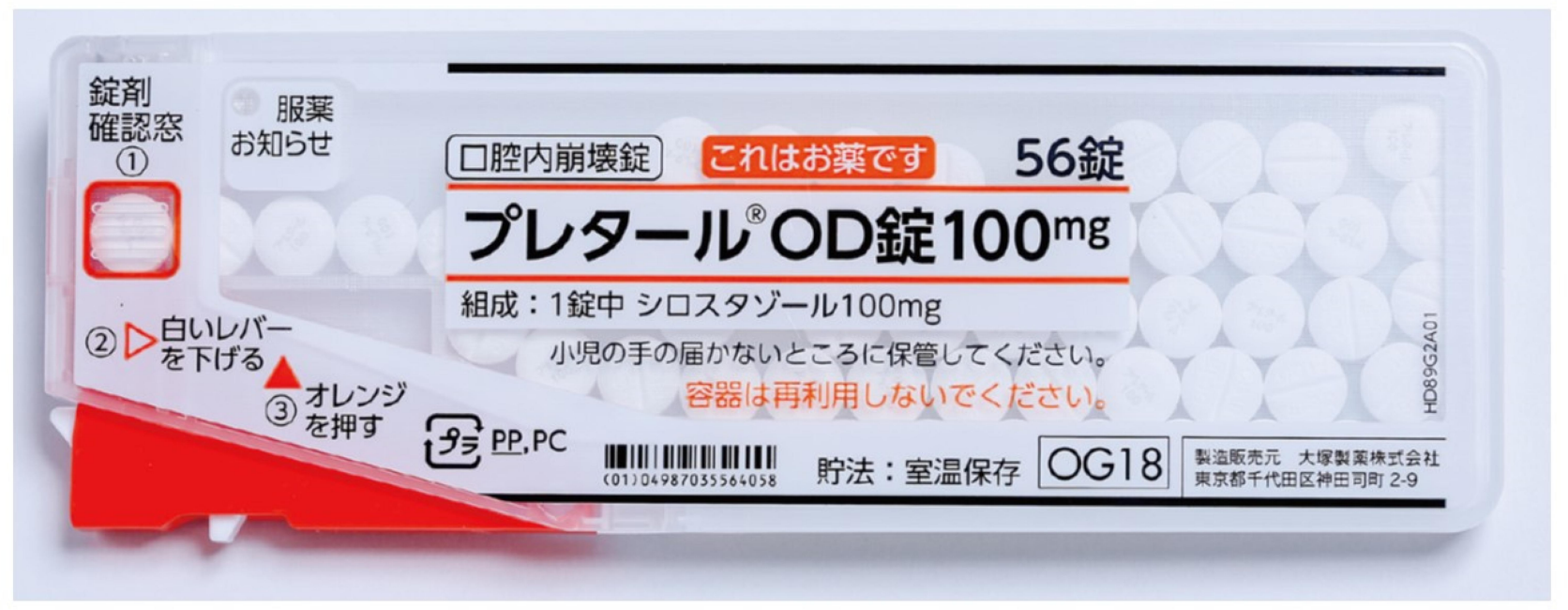

Figure I Labeling of the Pletaal Assist System ${ }^{\circledR}$, as it appeared to the patients.

consent to participate in the study (before PAS use), $12 \pm 2$ weeks after starting PAS, and $12 \pm 2$ weeks after stopping PAS use (Figure 2). The 2-week gap before and after each visit was considered acceptable. The appropriate intake rate, which was calculated as the number of times that the drug was taken out at the appropriate time/the number of pills prescribed at outpatient clinic, was also evaluated during PAS period only. Appropriate time was defined as $\geq 6$ $\mathrm{h}$ and $\leq 18 \mathrm{~h}$ from the time of the previous instance of the drug being taken out. There were no interventions from nurses or pharmacists during the study period.

\section{Blood and Medical Examinations}

The values of casual blood pressure (taken during outpatient visits), low-density lipoprotein (LDL) cholesterol, and haemoglobin A1c (HbA1c) were obtained during study inclusion, the study period, and at the end of the study. Moreover, the following patient characteristics were investigated: age, sex, hypertension (casual blood pressure $\geq 140 / 90 \mathrm{mmHg}$ or medicated with regular antihypertensive drugs), diabetes mellitus (fasting blood glucose $\geq 126 \mathrm{mg} / \mathrm{dL}$, random blood glucose $\geq 200 \mathrm{mg} / \mathrm{dL}, \mathrm{HbA} 1 \mathrm{c} \geq 6.5 \%$, or taking antidiabetic medication), dyslipidaemia (serum total cholesterol $\geq 220 \mathrm{mg} / \mathrm{dL}$, triglycerides $>150 \mathrm{mg} / \mathrm{dL}$, or taking antihyperlipidemic drugs), stroke subtypes at index stroke, and current smoking habits. We also investigated whether the members of the patients' families could assist with the supervision of the patients' regular drug intake.

\section{Statistical Analysis}

Sample size: according to a study that investigated the post-discharge medication adherence rate of patients hospitalized for stroke or TIA: the percentage of patients who were still taking recurrence prevention medication at 3 months after discharge dropped to $75.5 \%{ }^{9}$ Based on these results, the required number of patients in each group was 5 , calculated as $\alpha=0.05, \beta=0.2$, effect size $=20 \%, \mathrm{SD}=0.1$, and the target number of patients in this study was 30. SPSS software version 25 (IBM Japan, Tokyo, Japan) was used for statistical analysis.

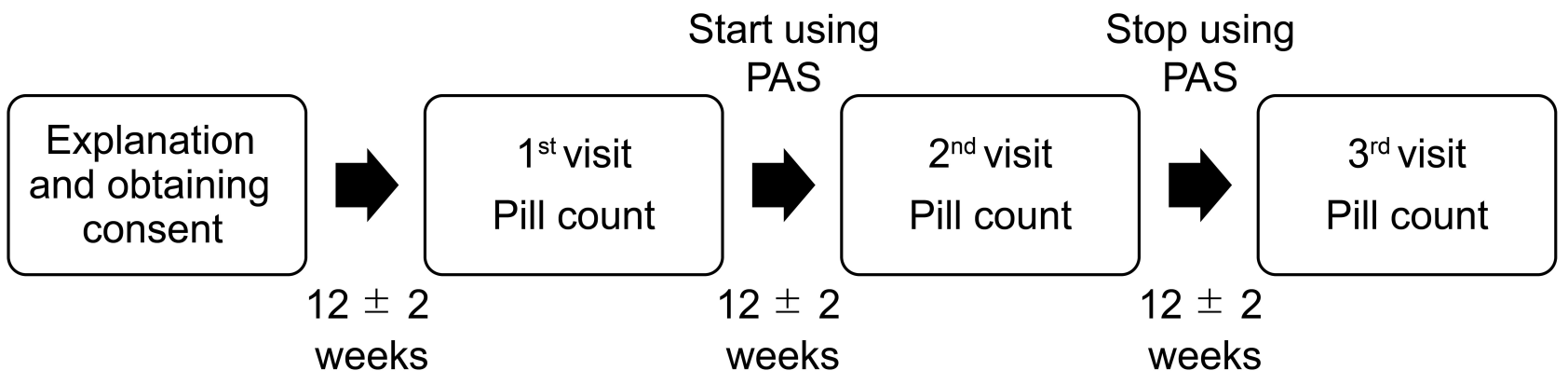

Figure 2 Flowchart of timing of patient pill intake along the study. 
Non-normally distributed data were analysed by the Wilcoxon signed-rank test. The Friedman test was used to assess differences in medication compliance rates before, during and after the PAS use, and the differences were considered statistically significant when the twotailed $\mathrm{p}<0.05$. Multiple comparisons of significant differences were corrected using the Bonferroni correction.

\section{Results}

\section{Study Population}

Screening was performed on 588 stroke patients who visited our outpatient clinic. Thirty-four patients met the eligibility criteria, and four patients were not enrolled because their consent was not obtained. Three patients enrolled but dropped out because they did not understand how to use the PAS; one patient dropped out because he developed heart failure, which is a contraindication for cilostazol, during the study period. One patient who violated the protocol was excluded. Finally, 25 patients were analyzed (median age, 68.5 years, ranged 51 to 86; male $64 \%$ ). All the participants were prescribed cilostazol $(100 \mathrm{mg})$ twice a day. Among them, 20 patients $(80 \%)$ had hypertension, 12 (48\%) had diabetes mellitus, and 13 (52\%) had dyslipidaemia. In total, 12 patients had a history of smoking, and only five patients were assisted by their family in taking the drugs.

\section{Monitoring and Recording Adherence with PAS}

The median adherence rate before implementing the PAS in all the patients was $100 \%$ (range $55-100$ ). There was no association between the adherence rate before implementing the PAS and the patients' background characteristics (Table 1). The index stroke subtypes were as follows: two large artery atherosclerosis, ten small vessel occlusions, and thirteen strokes of other aetiologies. Among these subtypes, the adherence rates before implementing the PAS were not statistically different as follows: $74.5 \%$ (median, range 55-94) of patients with large artery atherosclerosis, $100 \%(83-100)$ with small vessel occlusions, and $100 \%(77-100)$ with strokes of other aetiologies $(\mathrm{p}=0.05)$.

The median appropriate on-time drug intake rate while using the PAS for all patients was $98 \%$ (range 79-100). The appropriate on-time drug intake rate while using the PAS was lower for patients with current smoking habits than for those with no smoking habits ( $96 \%$ vs $99 \%, \mathrm{p}=0.03$ ) (Table 2$)$.
Table I Patient Characteristics and Adherence Rate Before Using the Pletaal Assist System ${ }^{\circledR}$

\begin{tabular}{|c|c|c|c|}
\hline Characteristics (n) & & $\begin{array}{c}\text { Median } \\
\text { Adherence Rate } \\
\% \text { (Range) }\end{array}$ & $P$ value \\
\hline \multirow[t]{2}{*}{ Male (16) } & Yes & $99.5(55-100)$ & \multirow[t]{2}{*}{0.21} \\
\hline & No & $100(90-100)$ & \\
\hline \multirow[t]{2}{*}{ Smoking (12) } & Yes & $98.5(55-100)$ & \multirow[t]{2}{*}{0.19} \\
\hline & No & $100(83-100)$ & \\
\hline \multirow[t]{2}{*}{ Support by family (5) } & Yes & $100(97-100)$ & \multirow[t]{2}{*}{0.65} \\
\hline & No & $100(55-100)$ & \\
\hline \multirow[t]{2}{*}{ Hypertension (20) } & Yes & $100(55-100)$ & \multirow[t]{2}{*}{0.43} \\
\hline & No & $100(97-100)$ & \\
\hline \multirow[t]{2}{*}{ Diabetes mellitus (12) } & Yes & $100(55-100)$ & \multirow[t]{2}{*}{0.60} \\
\hline & No & $100(77-100)$ & \\
\hline \multirow[t]{2}{*}{ Dyslipidemia (13) } & Yes & $100(55-100)$ & \multirow[t]{2}{*}{0.69} \\
\hline & No & $100(77-100)$ & \\
\hline
\end{tabular}

Table 2 Patient Characteristics and Appropriate On-Time Drug Intake During Implementation of the Pletaal Assist System ${ }^{\circledR}$

\begin{tabular}{|c|c|c|c|}
\hline Characteristics (n) & & $\begin{array}{c}\text { Median } \\
\text { Appropriate On- } \\
\text { Time Drug Intake } \\
\text { Rate \% (Range) }\end{array}$ & $P$ value \\
\hline \multirow[t]{2}{*}{ Male (8) } & Yes & $97(79-100)$ & \multirow[t]{2}{*}{0.07} \\
\hline & No & $99.5(94-100)$ & \\
\hline \multirow[t]{2}{*}{ Smoking (6) } & Yes & $96(79-100)$ & \multirow[t]{2}{*}{0.03} \\
\hline & No & $99(96-100)$ & \\
\hline \multirow[t]{2}{*}{ Support by family (2) } & Yes & $99.5(98-100)$ & \multirow[t]{2}{*}{0.06} \\
\hline & No & $97(79-100)$ & \\
\hline \multirow[t]{2}{*}{ Hypertension (8) } & Yes & $98(79-100)$ & \multirow[t]{2}{*}{0.64} \\
\hline & No & $98.5(92-100)$ & \\
\hline \multirow[t]{2}{*}{ Diabetes mellitus (4) } & Yes & $98(84-100)$ & \multirow[t]{2}{*}{0.80} \\
\hline & No & $97(79-100)$ & \\
\hline \multirow[t]{2}{*}{ Dyslipidemia (6) } & Yes & $98.5(79-100)$ & \multirow[t]{2}{*}{0.29} \\
\hline & No & $97(84-100)$ & \\
\hline
\end{tabular}

\section{Adherence-Improving Effect of PAS}

The changes in the adherence rates before, during, and after implementing PAS are shown in Figure 3. For all 


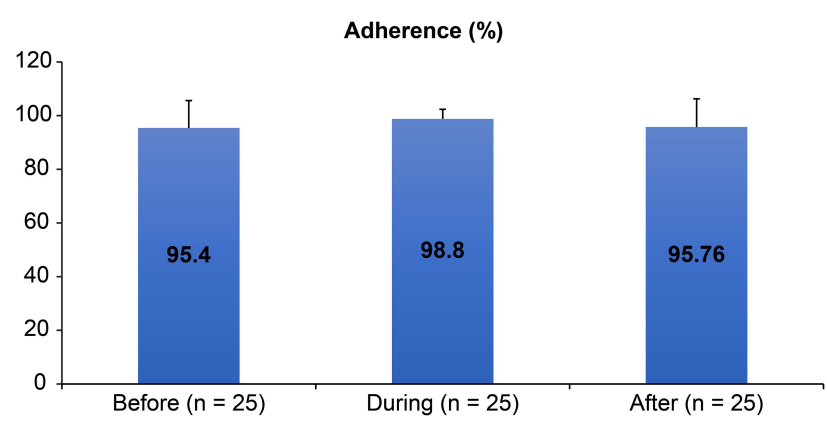

Figure 3 The compliance rates before, during, and after the implementation of the Pletaal Assist System ${ }^{\circledR}$ ( $n=25$ per group). There were no significant differences before, during, and after using the Pletaal Assist System ${ }^{\circledR}$.

patients, there was no significant difference in the adherence rate before (median; 100, range; 55-100), during (median; 100, range; 82-100), and after using the PAS (median; 100, range; 50-100). Vascular risk factors including casual blood pressure, LDL cholesterol, and $\mathrm{HbAlc}$ were comparable among these periods (Table 3). However, after excluding 15 patients with $100 \%$ adherence rate before implementing the PAS, the adherence rate changed during the study period. For patients whose adherence rate was less than $100 \%$, the adherence rate during PAS usage was higher than that before PAS usage $(99.5 \%$ vs $95 \%$, $\mathrm{p}=0.04$, Bonferroni correction), and the rate after using the PAS was lower compared to the rate during PAS usage (99.5\% vs 96\%, $\mathrm{p}=0.05$, Bonferroni correction) (Figure 4).

\section{Discussion}

Our pilot study demonstrates the feasibility and the usefulness of the PAS approach to monitor the adherence of cilostazol in outpatients with a history of stroke. For patients with current smoking habits, the rate of appropriate on-time intake during PAS usage was lower than for those with no smoking habits. Moreover, we showed that

Table 3 Casual Blood Pressure, Low-Density Lipoprotein Cholesterol, and HbAlc of All Patients Before, During, and After the Implementation of the Pletaal Assist System ${ }^{\circledR}$

\begin{tabular}{|l|c|c|c|}
\hline & Before & During & After \\
\hline SBP $(\mathrm{mmHg})$ & $130(84-174)$ & $132(106-187)$ & $130(95-157)$ \\
\hline DBP $(\mathrm{mmHg})$ & $75(48-99)$ & $78(58-96)$ & $77(58-94)$ \\
\hline LDL-C (mg/dL) & $87(52-116)$ & $87.5(52-131)$ & $93(44-127)$ \\
\hline HbAIc $(\%)$ & $6.1(5.3-10.1)$ & $6.1(5.4-9.4)$ & $6.05(5.3-10.1)$ \\
\hline
\end{tabular}

Note: Values are expressed as median (range).

Abbreviations: SBP, systolic blood pressure; DBP, diastolic blood pressure; LDLC, low-density lipoprotein cholesterol.

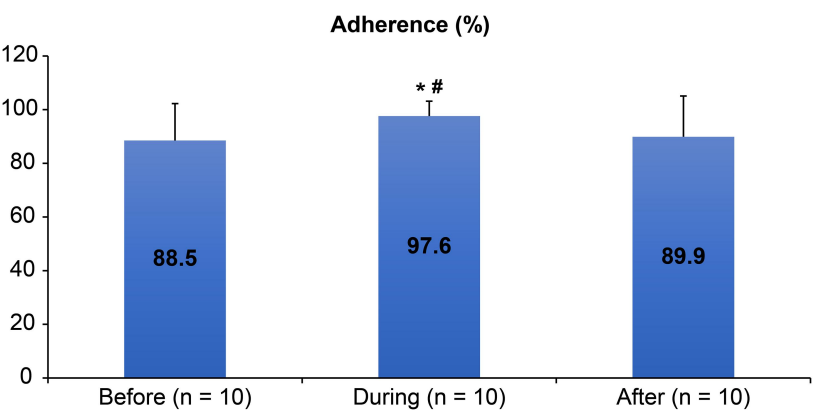

Figure 4 The compliance rate of patients whose compliance rate was less than $100 \%$ before using the Pletaal Assist System ${ }^{\circledR}$ ( $n=10$ per group). The compliance rate while using the Pletaal Assist System ${ }^{\circledR}$ was significantly higher than before and after using the Pletaal Assist System ${ }^{\circledR}$.

Notes: ${ }^{*} p<0.05$ during versus before, ${ }^{*} p<0.05$ during versus after.

the PAS could improve the adherence to cilostazol in patients whose adherence was not total prior to implementing the PAS.

There were several limitations. First, the pills were counted to assess the patient's adherence rates; however, this method might have overestimated the adherence rates because patients might switch drugs between bottles or discard pills before visits to appear to be adhering to their regimen. ${ }^{13}$ Hence, a pill count might not be considered as a good indicator of adherence. ${ }^{18-20}$ Second, the sample size was small, and the adherence rates of the patients were extremely high. The importance of adhering to medication during the study enrolment was explained to the participants and it was assumed that this may have affected the compliance rate. As such, the impact of the PAS on drug adherence may be underestimated. Third, the PAS could record the fact that the drug was removed from the device; however, it could not confirm whether the drug was indeed taken or not by the patients.

The Medication Event Monitoring System (MEMS) is the most commonly used EMP device in medication adherence research. This objective measurement system was reportedly accurate in several studies and healthcare professionals could identify whether non-adherence was sporadic, consistent, or whether patients had other abnormal medication patterns. ${ }^{21,22}$ Moreover, patients were less likely to not adhere when using a pill count because they needed to open the container at the same time each day if they wanted to discard the medication to ensure that the same adherence pattern was recorded. ${ }^{23}$ However, clinical studies on introducing a MEMS could be very costly because of the potential loss of equipment by patients, and the hardware and software rental required for data retrieval. Nevertheless, the PAS was supplied as a free 
device with a cilostazol prescription as this study was performed within the Japanese insurance coverage system, without any funding from industries or pharmacies.

It was assumed that the impact of the PAS on improving cilostazol adherence could be attributed to the dose frequency of the drug. Aspirin and clopidogrel are taken once-daily, but cilostazol is taken twice a day. It is known that decreasing the prescribed dose frequency improves compliance. ${ }^{24}$ Eisen et al reported that drug adherence improved from $59.0 \%$ with three doses per day to $83.6 \%$ with a once-daily dose. ${ }^{24}$ In addition, in a large systematic review of 76 trials using electronic monitors, Claxton et al reported that drug adherence was inversely proportional to the frequency of taking medication, with average adherence rates decreasing to approximately $50 \%$ for patients taking the drug on a four-times-a-day schedule. ${ }^{25}$

We also showed that the PAS was useful for improving the drug adherence and for observing whether patients were taking their drugs at the right time. We found that the rate of appropriate on-time intake was associated with smoking habits. Lower adherence has been reported in smokers. $^{26-28}$ Smoking is a risk factor for stroke and lower health literacy among smokers might be related to lower rates of administering pills at the right time. ${ }^{29}$

\section{Conclusion}

This pilot and feasibility study evaluated the usefulness of the PAS in monitoring cilostazol adherence in outpatients with a history of stroke. The PAS could significantly improve the adherence for cilostazol in outpatients whose adherence was insufficient.

\section{Abbreviations}

CVD, cardiovascular disease; EMP, Electronic Medication Packaging; LDL, low-density lipoprotein; MEMS, Medication Event Monitoring System; PAS, Pletaal Assist System ${ }^{\circledR}$.

\section{Acknowledgments}

We would like to thank Editage for editing and reviewing this manuscript.

\section{Funding}

This research received no specific grant from any funding agency in the public, commercial, or not-for-profit sectors.

\section{Disclosure}

The authors declare no conflicts of interest.

\section{References}

1. McDonnell PJ, Jacobs MR. Hospital admissions resulting from preventable adverse drug reactions. Ann Pharmacother. 2002;36 (9):1331-1336. doi:10.1345/aph.1A333

2. Schiff GD, Fung S, Speroff T, McNutt RA. Decompensated heart failure: symptoms, patterns of onset, and contributing factors. $\mathrm{Am}$ $J$ Med. 2003;114(8):625-630. doi:10.1016/S0002-9343(03)00132-3

3. Senst BL, Achusim LE, Genest RP, et al. Practical approach to determining costs and frequency of adverse drug events in a health care network. Am J Health-Syst Pharm. 2001;58(12):1126-1132. doi:10.1093/ajhp/58.12.1126

4. Misdrahi D, Llorca PM, Lançon C, Bayle FJ.L'observance dans la schizophrénie: facteurs prédictifs, voies de recherches, implications thérapeutiques [Compliance in schizophrenia: predictive factors, therapeutical considerations and research implications]. Encephale. 2002;28(3 Pt 1):266-272.

5. Rodgers PT, Ruffin DM. Medication nonadherence: part II - a pilot study in patients with congestive heart failure. Manag Care Interface. 1998;11(9):67-69,75.

6. Sandercock PAG, Counsell C, Tseng MC, Cecconi E. Oral antiplatelet therapy for acute ischaemic stroke. Cochrane Database Syst Rev. 2014;(3):CD000029.

7. Maulaz AB, Bezerra DC, Michel P, Bogousslavsky J. Effect of discontinuing aspirin therapy on the risk of brain ischemic stroke. Arch Neurol. 2005;62(8):1217-1220. doi:10.1001/archneur.62.8.1217

8. Glader EL, Sjolander M, Eriksson M, Lundberg M. Persistent use of secondary preventive drugs declines rapidly during the first 2 years after stroke. Stroke. 2010;41(2):397-401. doi:10.1161/ STROKEAHA.109.566950

9. Bushnell CD, Zimmer LO, Pan W, et al. Persistence with stroke prevention medications 3 months after hospitalization. Arch Neurol. 2010;67(12):1456-1463. doi:10.1001/archneurol.2010.190

10. Chowdhury R, Khan H, Heydon E, et al. Adherence to cardiovascular therapy: a meta-analysis of prevalence and clinical consequences. Eur Heart J. 2013;34(38):2940-2948. doi:10.1093/eurheartj/eht295

11. Walsh JC, Mandalia S, Gazzard BG. Responses to a 1 month self-report on adherence to antiretroviral therapy are consistent with electronic data and virological treatment outcome. AIDS. 2002;16 (2):269-277. doi:10.1097/00002030-200201250-00017

12. Haynes RB, Taylor DW, Sackett DL, Gibson ES, Bernholz CD, Mukherjee J. Can simple clinical measurements detect patient noncompliance? Hypertension. 1980;2(6):757-764. doi:10.1161/01. HYP.2.6.757

13. Osterberg L, Blaschke T. Adherence to medication. $N$ Engl J Med. 2005;353(5):487-497. doi:10.1056/NEJMra050100

14. Checchi KD, Huybrechts KF, Avorn J, Kesselheim AS. Electronic medication packaging devices and medication adherence: a systematic review. JAMA. 2014;312(12):1237-1247. doi:10.1001/ jama.2014.10059

15. Kimura Y, Tani T, Kanbe T, Watanabe K. Effect of cilostazol on platelet aggregation and experimental thrombosis. Arzneimittelforschung. 1985;35(7A):1144-1149.

16. Yasunaga K, Mase K. Antiaggregatory effect of oral cilostazol and recovery of platelet aggregability in patients with cerebrovascular disease. Arzneimittelforschung. 1985;35(7A):1189-1192.

17. Shinohara Y, Katayama Y, Uchiyama S, et al. Cilostazol for prevention of secondary stroke (CSPS 2): an aspirin-controlled, double-blind, randomised non-inferiority trial. Lancet Neurol. 2010;9(10):959-968. doi:10.1016/S1474-4422(10)70198-8

18. Rudd P, Byyny RL, Zachary V, et al. Pill count measures of compliance in a drug trial: variability and suitability. Am J Hypertens. 1988;1(3 Pt 1):309-312. doi:10.1093/ajh/1.3.309

19. Pullar T, Kumar S, Tindall H, Feely M. Time to stop counting the tablets? Clin Pharmacol Ther. 1989;46(2):163-168. doi:10.1038/ clpt.1989.121 
20. Cramer JA, Mattson RH, Prevey ML, Scheyer RD, Ouellette VL. How often is medication taken as prescribed? A novel assessment technique. JAMA. 1989;261(22):3273-3277. doi:10.1001/jama.1989. 03420220087032

21. Svarstad BL, Chewning BA, Sleath BL, Claesson C. The brief medication questionnaire: a tool for screening patient adherence and barriers to adherence. Patient Educ Couns. 1999;37(2):113-124. doi:10.1016/S0738-3991(98)00107-4

22. Alili M, Vrijens B, Demonceau J, Evers SM, Hiligsmann M. A scoping review of studies comparing the medication event monitoring system (MEMS) with alternative methods for measuring medication adherence. Br J Clin Pharmacol. 2016;82(1):268-279. doi:10.1111/bcp. 12942

23. Diaz E, Levine HB, Sullivan MC, et al. Use of the medication event monitoring system to estimate medication compliance in patients with schizophrenia. J Psychiatry Neurosci. 2001;26(4):325-329.

24. Eisen SA, Miller DK, Woodward RS, Spitznagel E, Przybeck TR. The effect of prescribed daily dose frequency on patient medication compliance. Arch Intern Med. 1990;150(9):1881-1884. doi:10.1001/ archinte.1990.00390200073014
25. Claxton AJ, Cramer J, Pierce C. A systematic review of the associations between dose regimens and medication compliance. Clin Ther. 2001;23(8):1296-1310. doi:10.1016/S0149-2918(01)80109-0

26. Han E, Sohn HS, Lee J-Y, Jang S. Health behaviors and medication adherence in elderly patients. Am J Health Promot. 2017;31 (4):278-286. doi:10.4278/ajhp.150205-QUAN-709

27. Crowley MJ, Zullig LL, Shah BR, et al. Medication non-adherence after myocardial infarction: an exploration of modifying factors. $J$ Gen Intern Med. 2015;30(1):83-90. doi:10.1007/s11606-0143072-x

28. Juarez DT, Williams AE, Chen C, et al. Factors affecting medication adherence trajectories for patients with heart failure. Am J Manag Care. 2015;21(3):e197-e205.

29. Pan B, Jin X, Jun L, Qiu S, Zheng Q, Pan M. The relationship between smoking and stroke: a meta-analysis. Medicine (Baltimore). 2019;98 (12):e14872. doi:10.1097/MD.0000000000014872
Patient Preference and Adherence

\section{Publish your work in this journal}

Patient Preference and Adherence is an international, peer-reviewed, open access journal that focusing on the growing importance of patient preference and adherence throughout the therapeutic continuum. Patient satisfaction, acceptability, quality of life, compliance, persistence and their role in developing new therapeutic modalities and compounds to optimize clinical outcomes for existing disease

\section{Dovepress}

states are major areas of interest for the journal. This journal has been accepted for indexing on PubMed Central. The manuscript management system is completely online and includes a very quick and fair peer-review system, which is all easy to use. Visit http:// www.dovepress.com/testimonials.php to read real quotes from published authors. 